\title{
High dose pancreatic enzymes in cystic fibrosis
}

\author{
P J Robinson, P D Sly
}

\begin{abstract}
Seven patients with cystic fibrosis taking high doses of pancreatin supplements were assessed to determine whether this dose was necessary to achieve adequate fat absorption. Patients reduced their intake from a group mean of $\mathbf{4 5}$ to 21 capsules a day. Five patients did not have any significant alteration in fat malabsorption while taking the reduced enzyme dose.
\end{abstract}

While $90 \%$ of patients with cystic fibrosis require pancreatic enzyme (pancreatin) supplements, wide interpatient variation in the individual dosage requirement exists. Most clinicians rely on symptoms such as failure to gain weight or the passage of offensive bulky bowel actions to regulate the enzyme dose. By increasing enzyme dose in the face of such symptoms the clinician is making two assumptions. Firstly, that the symptoms are due to insufficient pancreatic enzyme function in the small bowel, and secondly that a further increase in enzyme administration will improve fat absorption. However, abdominal symptoms in patients with cystic fibrosis are not invariably related to pancreatic enzyme insufficiency. ${ }^{12}$ Increasing enzyme supplementation in the presence of such abdominal symptoms would not be expected to relieve the symptoms or to improve absorption.

The cystic fibrosis clinic at the Royal Children's Hospital, Melbourne, cares for approximately 350 children below the age of 18 years. We were concerned that some of our patients were taking excessive doses of pancreatin supplementation unnecessarily. We therefore studied a group of patients taking high doses of enzymes to determine whether a reduction in the enzyme dose could be achieved without a deterioration in fat absorption. This study was performed as a preliminary to an investigation of patients unable to achieve normal fat absorption despite taking large quantities of pancreatic enzymes.

\section{Patients and methods}

Seven patients with cystic fibrosis (mean age 10.7 years, range 9-14 years) who were taking large doses of pancreatin were studied. Patients were included if they had persistent abdominal symptoms, such as offensive bulky stools or abdominal pain, failure to gain weight, or because of concern that they may not require their high enzyme input (table 1). Two patients (cases 5 and 6) presented at birth with meconium ileus, which required limited bowel resection. All patients had a daily fat intake exceeding $2 \mathrm{~g} / \mathrm{kg}$ and documented fat malabsorption, which improved with the addition
Table 1 Anthropomorphic data

\begin{tabular}{|c|c|c|c|}
\hline $\begin{array}{l}\text { Case } \\
\text { No }\end{array}$ & $\begin{array}{l}\text { Age } \\
\text { (years) }\end{array}$ & Sex & Reason for enrolment \\
\hline $\begin{array}{l}1 \\
2 \\
3 \\
4 \\
5 \\
6 \\
7\end{array}$ & $\begin{array}{r}11 \\
9 \\
11 \\
14 \\
9 \\
11 \\
10\end{array}$ & $\begin{array}{l}M \\
M \\
M \\
M \\
M \\
F \\
M\end{array}$ & $\begin{array}{l}\text { Abdominal pain, offensive stools } \\
\text { Failure to gain weight } \\
\text { High enzyme intake } \\
\text { Abdominal pain, offensive stools } \\
\text { Offensive stools, high enzyme intake } \\
\text { Poor weight gain, high enzyme intake } \\
\text { Abdominal pain, high enzyme intake }\end{array}$ \\
\hline
\end{tabular}

of enzyme supplements. All were currently taking pancreatin supplements in the form of enteric coated microspheres (Pancrease, Cilag, 5000 units lipase/capsule).

Two outpatient three day faecal fat balance studies were performed, separated by a minimum of three weeks and a maximum of six weeks. Before the second study patients were counselled how to reduce their enzyme dose, following an individual regimen, to approximately 30 capsules per day. The selection of 30 capsules as the modified dosage was arbitrary but is a figure frequently suggested at cystic fibrosis meetings as a maximal dose. The modified enzyme regimen was used for five days before the faecal collection commenced. Faecal fat analysis was performed using the acid titration method of van de Kramer $e t a l^{3}$ and oral input of fat was determined using the Microdiet programme (Department of Statistics and Mathematics, University of Salford), modified for local food values.

Informed consent was obtained from each patient and at least one parent before enrollment. The study protocol was approved by the hospital ethics committee.

\section{Results}

All parents and the older patients enrolled in this study expressed concern at the start of the study as to the likely occurrence of offensive stools and abdominal pain with the reduction of the enzyme input. Patients reduced their intake of pancreatin from a group mean of 45 capsules per day to a group mean of 21 (table 2).

Five patients had normal fat absorption on their usual pancreatin dose while two had considerable malabsorption. Five patients did not have any appreciable alteration in fat malabsorption while taking the modified enzyme schedule. These included four with normal absorption and one with $16 \%$ malabsorption on the usual enzyme dosage. The two remaining patients experienced large increases in fat malabsorption with the reduction in enzyme dosage. Fat intake was not appreciably different in the two study periods.

The two patients who had previous bowel resection for meconium ileus both achieved 
Table 2 Number of pancreatin capsules* taken and fat malabsorption (\%) while taking usual and modified pancreatin doses

\begin{tabular}{|c|c|c|c|c|}
\hline \multirow[t]{2}{*}{ Case No } & \multicolumn{2}{|c|}{ Usual pancreatin dose } & \multicolumn{2}{|c|}{ Modified pancreatin dose } \\
\hline & No of capsules & $\%$ Malabsorptiont & No of capsules & $\%$ Malabsorptiont \\
\hline $\begin{array}{l}1 \\
2 \\
3 \\
4 \\
5 \\
6 \\
7\end{array}$ & $\begin{array}{l}39 \\
37 \\
51 \\
45 \\
50 \\
44 \\
46\end{array}$ & $\begin{array}{r}5 \\
16 \\
8 \\
22 \\
7 \\
7 \\
5\end{array}$ & $\begin{array}{l}18 \\
18 \\
20 \\
27 \\
28 \\
19 \\
19\end{array}$ & $\begin{array}{r}6 \\
18 \\
39 \\
43 \\
5 \\
10 \\
6\end{array}$ \\
\hline
\end{tabular}

${ }^{*}$ Capsule numbers refer to an average daily intake.

$\dagger \%$ Malabsorption refers to the percentage of orally ingested fat malabsorbed, as determined by a three day fat balance study.

reductions in their enzyme intake without appreciable alteration in their absorption. Both these patients achieved normal fat absorption with the reduced enzyme dose.

\section{Discussion}

This study has shown that some patients with cystic fibrosis take inappropriately high doses of pancreatic enzymes and that reduction of this high input may be achieved without deterioration in fat absorption. However, two of the patients did have an increase in fat malabsorption when their enzyme dose was decreased. This argues against a policy of setting an arbitrary limit to the enzyme dose, as is frequently suggested at cystic fibrosis clinical meetings. All patients in this study had reached their current dose of enzymes in response to symptoms perceived as due to residual malabsorption This study highlights the risks of assuming that abdominal symptoms in patients with cystic fibrosis are invariably due to pancreatic enzyme insufficiently and therefore will respond to an increase in enzyme treatment; five of the seven subjects had normal absorption despite persisting symptoms.

The major implication of the results of the present study is that objective assessment of nutrient absorption should be routine in patients with cystic fibrosis, particularly those with abdominal symptoms. The best of the currently available tests is the three day faecal fat balance. This procedure is time consuming, prone to large errors if not performed correctly, and rarely welcomed by patients. The results of the present study, however, illustrate the importance of assessing changes in enzyme treatment by direct measurements of nutrient absorption.

In conclusion the present study has shown that some children with cystic fibrosis may be taking inappropriately high doses of pancreatic enzymes because of abdominal symptoms not directly related to exocrine pancreatic insufficiency. It is important to determine whether symptoms are due to fat malabsorption and that increases in enzyme replacement result in improved absorption. Recognition of other potential causes of abdominal symptoms in cystic fibrosis should lead to a more logical approach to the patient with residual symptoms on standard enzyme treatment.

The authors wish to thank Mrs B Crawford who performed the faecal fat assays. This work was supported by a grant from the Royal Children's Hospital Research Foundation. The financial assistance of Organon is gratefully acknowledged. 1 Baxter PS, Dickson JAS, Variend S, Taylor CJ. Intestinal disease in cystic fibrosis. Arch Dis Child 1988;63:1496-7.
Gaskin KJ, Waters DLM, Howman-Giles R, et al. Liver disease and common bile duct stenosis in cystic fibrosis. $N$ Engl $f$ Med 1988;318:340-6.

3 van de Kramer JH, ten Bokkel Huinink H, Weyers HA. Rapid method for the determination of fat in faeces. $\mathcal{f}$ Biol Chem 1949;177:347-55.

\section{Dexamethasone treatment for congenital adrenal hyperplasia}

M C Young, I A Hughes

\section{Department of Child Health University of Wales College of Medicine, Cardiff \\ M C Young \\ I A Hughes \\ Correspondence to: Professor IA Hughes,} University Department of Paediatrics, Addenbrooke's Hospital Level E8, Hills Road, Cambridge CB2 200.

Accepted 8 November 1989

\begin{abstract}
Ten patients with congenital adrenal hyperplasia (three males, seven females; aged 12-29 years) had their usual glucocorticoid treatment changed to dexamethasone in three crossover dosage regimens. A starting dose of $5 \mu \mathrm{g} / \mathrm{kg} / \mathrm{day}$ is suggested but as no one dose regimen resulted in adequate control the timing of the dose must be decided for each patient.
\end{abstract}

The optimum glucocorticoid preparation, total daily dose, and dose schedule for the treatment of congenital adrenal hyperplasia remain controversial. ${ }^{1}$ Hydrocortisone is probably the preparation of choice in infancy and childhood, but in adolescents near completion of growth and adults dexamethasone may be a convenient alternative. ${ }^{1-3}$ The potency of dexamethasone in relation to both pituitary-adrenal suppression and side effects is much greater.

\section{Patients}

Ten patients (three males and seven females) aged 12-29 years with 21-hydroxylase deficiency (classic salt losing type) congenital adrenal hyperplasia took part in the study. 